\title{
Effect of Wearing the Elevation Training Mask on Aerobic Capacity, Lung Func- tion, and Hematological Variables
}

\author{
John P. Porcari ${ }^{1}$, Lauren Probst ${ }^{1}$, Karlei Forrester ${ }^{1}$, Scott Doberstein ${ }^{1}$, Carl Foster ${ }^{1}$, Maria L. \\ Cress ${ }^{1}$ and Katharina Schmidt ${ }^{2}$ \\ ${ }^{1}$ University of Wisconsin- La Crosse, USA; ${ }^{2}$ University of Frankfurt, Frankfurt, Germany
}

\begin{abstract}
Altitude training and respiratory muscle training (RMT) have been reported to improve performance in elite and well-trained athletes. Several devices (altitude and RMT) have been developed to help athletes gain the competitive edge. The Elevation Training Mask 2.0 (ETM) purportedly simulates altitude training and has been suggested to increase aerobic capacity $\left(\mathrm{VO}_{2} \mathrm{max}\right)$, endurance performance, and lung function. Twentyfour moderately trained subjects completed 6 weeks of highintensity cycle ergometer training. Subjects were randomized into a mask $(n=12)$ or control $(n=12)$ group. Pre and posttraining tests included $\mathrm{VO}_{2}$ max, pulmonary function, maximal inspiration pressure, hemoglobin and hematocrit. No significant differences were found in pulmonary function or hematological variables between or within groups. There was a significant improvement in $\mathrm{VO}_{2} \max$ and $\mathrm{PPO}$ in both the control $13.5 \%$ and $9.9 \%)$ and mask (16.5\% and $13.6 \%$ ) groups. There was no difference in the magnitude of improvement between groups. Only the mask group had significant improvements in ventilatory threshold (VT) (13.9\%), power output (PO) at VT (19.3\%), respiratory compensation threshold (RCT) (10.2\%), and PO at RCT (16.4\%) from pre to post-testing. The trends for improvements in VT and PO at VT between groups were similar to improvements in RCT and PO at RCT, but did not reach statistical significance $(\mathrm{VT} p=0.06, \mathrm{PO}$ at VT $\mathrm{p}=0.170)$. Wearing the ETM while participating in a 6-week high-intensity cycle ergometer training program does not appear to act as a simulator of altitude, but more like a respiratory muscle training device. Wearing the ETM may improve specific markers of endurance performance beyond the improvements seen with interval training alone.
\end{abstract}

Key words: Altitude training, interval training.

\section{Introduction}

It is well known that athletic endurance performance has significantly improved over the last several years. In order to remain competitive, athletes and coaches are constantly looking for ways to enhance performance. Several training methods have been explored in order to find the best method to enhance athletic performance. Altitude training and respiratory muscle training (RMT) are two methods that have shown promise in increasing athletic performance.

Balke et al. (1965) were some of the first to observe the benefits of altitude training while exploring the potential effects of altitude on the 1968 Olympic Games. Balke et al. (1965) observed that aerobic work capacity was enhanced upon returning to low altitude (400 m) from training at moderate altitude $(2300 \mathrm{~m})$. Since then, many others have studied the effects of altitude training on performance in well-trained or elite athletes (Buchheit et al., 2012; Daniels and Oldridge, 1969; Julian et al., 2003; Levine and Stray-Gundersen, 1997; McLean et al., 2014; Robertson et al., 2010; Stray-Gundersen et al., 2001). The "live high-train low" method has been accepted as one of the better methods to obtain the benefits of altitude training. Using this method, athletes live at moderate altitude $(2,500 \mathrm{~m})$ and train at low altitude $(1,250 \mathrm{~m})$ which allows athletes to obtain the benefits of altitude acclimatization and continue to train at high intensities, resulting in improvements of aerobic capacity $\left(\mathrm{VO}_{2} \mathrm{max}\right)$, ventilatory threshold (VT) and performance at sea level (Chapman et al., 1998; Levine and Stray-Gundersen, 1997; Levine et al., 1991; Mattila and Rusko, 1996; Roberts et al., 2003; Rusko et al., 1999). It has been suggested that in order to obtain the benefits of acclimatized altitude training the athlete must spend at least 12 hours a day for at least 3 weeks at an altitude of $2100-2500 \mathrm{~m}$ (Rusko et al., 2004). This exposure to hypoxic conditions stimulates the kidneys to produce erythropoietin (EPO), which increases red blood cell (RBC) production (Paula and Niebauer, 2012). The increase in circulating RBC's increases the oxygen carrying capacity of the blood which has been correlated to improvements in $\mathrm{VO}_{2} \max$ and endurance performance at sea level using the "live high-train low" method (Levine and Stray-Gundersen, 1997; StrayGundersen and Levine, 2001).

Another tool used to improve exercise performance is RMT. The respiratory system has been identified as limiting factor in exercise performance in trained and sedentary individuals (Boutellier et al., 1992; Boutellier and Piwko, 1992). Markov et al. (2001) reported that RMT increased cycling endurance without evoking changes in stroke volume or $\mathrm{VO}_{2}$, indicating that performance improvements may be seen independently of the cardiovascular enhancements typically seen with endurance training. Romer et al. (2002) evaluated the effects of inspiratory muscle training (IMT) on endurance performance and inspiratory muscle fatigue in trained cyclists. It was found that 6 weeks of IMT resulted in a decrease in inspiratory muscle fatigue as well as improvements in time trial performance. In an effort to determine what intensity of IMT will provide an adequate training stimulus, Enright and Unnithan (2011) conducted a study looking at responses to 8 -weeks of IMT at $40 \%, 60 \%$, and $80 \%$ of sustained maximal inspiratory pressure (SMIP). While all IMT groups significantly increased SMIP and 
maximal inspiratory pressure (MIP), only participants in the $60 \%$ and $80 \%$ SMIP groups increased work capacity and power output (PO). More studies are needed to determine the exact resistance needed during IMT to promote positive performance changes.

The successful use of RMT to improve exercise performance has led researchers to investigate the benefits of resistance breathing during exercise. Kido et al. (2013) conducted a 6-week training study comparing the physiologic responses of using breathing resistance during continuous exercise to continuous exercise alone; breathing resistance was provided by a ReBNA mask-like device with valves providing inspiratory and expiratory resistance. It was found that training between $75 \%$ and $85 \%$ of HRR improved $\mathrm{VO}_{2}$ peak significantly in both exercise only $(11.7 \%)$ and resistance breathing (18.5\%) groups. However, only training with breathing resistance significantly increased maximal load (11.5\%) and VT (36\%) after training. This suggests that greater improvements in performance may be seen by combining breathing resistance with exercise training. However, the study by Kido et al. (2013) only had 5 subjects in the mask group, so it was concluded that the effectiveness of resistance breathing on exercise performance required further examination.

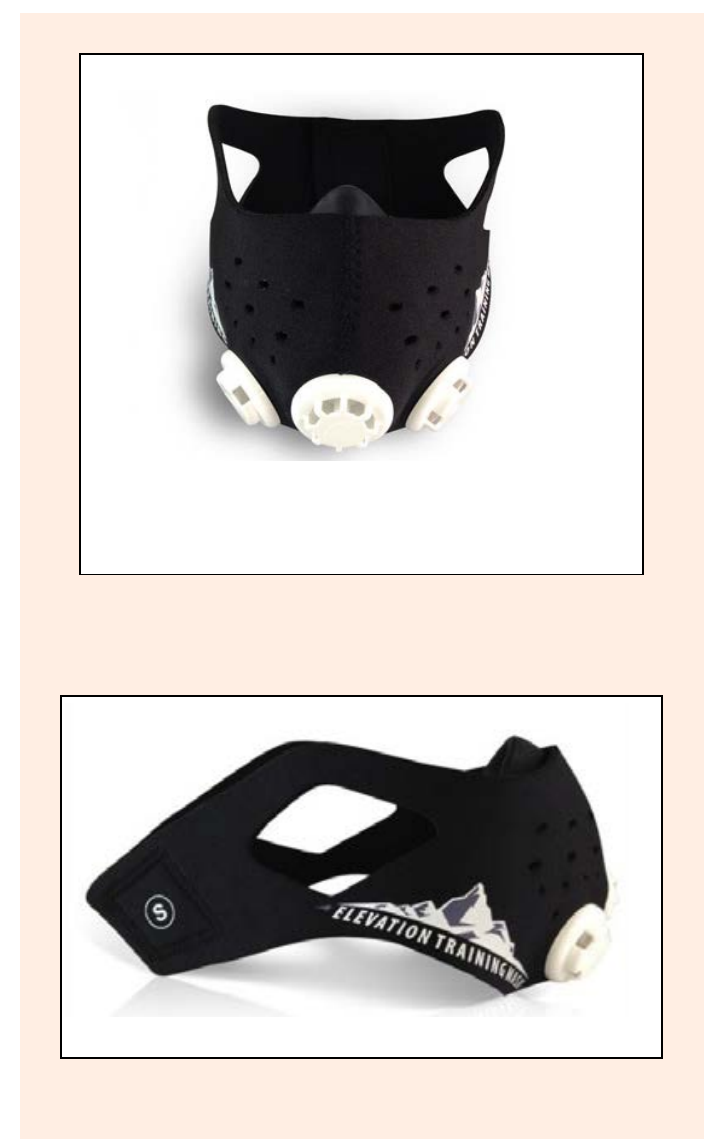

Figure 1. Elevation training mask.

The Elevation Training Mask 2.0 (ETM) (Training Mask LLC, Cadillac, Michigan) is a new product on the market that claims to enhance athletic performance. The ETM covers the nose and mouth and has different sized openings and flux valves (Figure 1). The openings and flux valves can be adjusted to increase the resistance of respiration, making it more difficult to breathe while wearing the mask. It is suggested that the device can increase endurance and $\mathrm{VO}_{2} \mathrm{max}$, as well as improve lung function. The multi-level resistance system purportedly allows the user to simulate altitudes ranging from $914 \mathrm{~m}$ to $5486 \mathrm{~m}$. However, in order to simulate altitude, the mask must have a mechanism to decrease partial pressure of oxygen, inducing a hypoxic state during exercise. Therefore, the purpose of this study was twofold: 1) determine the effects of wearing the ETM on endurance performance variables, and 2) determine if the ETM acts like an altitude simulator.

\section{Methods}

\section{Subjects}

Twenty-five (16 males, 9 females) students from the University of Wisconsin-La Crosse volunteered to participate in the study (Table 1). Students were moderately trained but had not been on a cycling training program in the previous 6 months. Each subject provided written informed consent. The study was approved by the University of Wisconsin-La Crosse Institutional Review Board for the Protection of Human Subjects.

\section{Procedures}

Pilot testing using three individuals was conducted prior to the start of the study in order to determine suitable training workloads for exercise and recovery, and simulated altitude settings for the mask. Testing was performed on Monark 828E Ergomedic cycle ergometers (Monark Exercise AB, Vansbro, Sweden).

Initially, each subject completed a maximal cycle ergometer test to determine $\mathrm{VO}_{2} \max$, VT, respiratory compensation threshold (RCT), maximal heart rate (MHR), and peak power output (PPO). The $\mathrm{VO}_{2}$ max test was performed on an electronically-braked cycle ergometer (Lode B.V., Groningen, Netherlands). The test began at $25 \mathrm{~W}$ for 3 minutes and PO was increased by $25 \mathrm{~W}$ every minute until volitional fatigue. Respiratory gas exchange was measured using a mixing chamber based, open-circuit spirometry system (AEI Technologies, Naperville, IL). Heart rate was measured every minute using radiotelemetry (Polar Vantage XL, Polar Instruments, Port Washington, NY) and ratings of perceived exertion (RPE) were assessed each minute using the modified Borg CR-10 scale (Borg, 1982).

Ventilatory threshold and RCT were measured using a combination of the $\mathrm{V}$-slope and ventilatory equivalent methods (Foster and Cotter, 2006). Ventilatory threshold was defined as when $\mathrm{VCO}_{2}$ increased disproportionately to $\mathrm{VO}_{2}$ and when $\mathrm{VE} / \mathrm{VO}_{2}$ increased relative to $\mathrm{VO}_{2}$, without $\mathrm{VE} / \mathrm{VCO}_{2}$ increasing. Respiratory compensation threshold was defined as when $\mathrm{VE}$ increased disproportionately to $\mathrm{VCO}_{2}$ and when both $\mathrm{VE} / \mathrm{VO}_{2}$ and $\mathrm{VE} / \mathrm{VCO}_{2}$ increased relative to $\mathrm{VO}_{2}$. All tests were interpreted by an experienced evaluator, who was blinded to subject identity, group assignment, and trial order (pre vs. posttest).

Pulmonary function was assessed for each subject. 
Forced vital capacity (FVC) and forced expiratory capacity in 1 second $\left(\mathrm{FEV}_{1}\right)$ were determined using a Spirometry System (ParvoMedics Inc., Sandy, UT). Maximal inspiratory pressure was assessed using a digital pressure vacuum meter (Net Tech, Farmingdale, NY). Hematocrit (Hct) was assessed using a capillary tube and Micro Hematocrit Centrifuge (International Equipment Co., Needham Heights, Mass. USA), and hemoglobin concentration $[\mathrm{Hb}]$ was determined for each subject using a hemoglobin reagent set and hemoglobin standard (Pointe Scientific Inc., Canton, MI), analyzed spectrophotmetrically (Spectronic 20D+, Thermospectronic, Rochester, NY).

Subjects were ranked based upon preliminary $\mathrm{VO}_{2} \max$ results and divided into two groups. The two groups were the mask group and a control group. The mask group wore the ETM for all training sessions, while the control group did not wear the mask during training. Both groups completed identical training programs.

All subjects completed two workouts during the week prior to training, in order to become familiar with the training protocol and equipment. For the first session, subjects in the mask group sat in the laboratory for 10 minutes while wearing the ETM (set at $914 \mathrm{~m}$ ) in order to become accustomed to breathing while wearing the mask. They then rode for 10 minutes at a self-selected pace on the mechanically braked cycle ergometers that would be used for training. For the first practice session, the control group also rode the cycle ergometers for 10 minutes at a self-selected pace. For the second practice session, both groups completed five, 30-second, interval bouts at peak PO, with 90 seconds active recovery between intervals. The mask group wore the ETM for this session while the control group did not.

\section{Training}

Subjects then completed a 6-week high-intensity cycle ergometer interval training program. Training sessions were held twice a week and each session was 30 minutes in length. Training was performed on the same ergometers as the pilot testing. For each workout, subjects completed a 5-minute warm-up, 20 minutes of high-intensity intervals, and a 5-minute cool-down. The 20-minute interval segment of the workload included 10 repetitions of 30 seconds at PPO (from the final stage of the $\mathrm{VO}_{2}$ max test), followed by a 90-second active recovery period. During the active recovery both groups worked at $25 \mathrm{~W}$. During each training session, subjects wore a HR monitor. Heart rate was recorded at the end of the high-intensity portion of each interval. Ratings of perceived exertion, using the CR-10 modified Borg scale, were also recorded after the high-intensity portion of each interval. At the end of the workout, session RPE was recorded (Foster et al., 2001).

Training intensity throughout the 6-week training period was titrated based on the subjects' RPE after interval 10 during their workout. If the control group rated the last interval $\leq 5$ (hard) for two consecutive sessions, then the PO was increased by $0.5 \mathrm{~kg}(\approx 30 \mathrm{~W})$ for the next training session. Similarly, if the mask group rated the last interval $\leq 7$ (very hard) for two consecutive sessions, then the PO was increased by $0.5 \mathrm{~kg}(\approx 30 \mathrm{~W})$ for the next training session. During pilot testing, at identical workloads, when subjects wore the mask, they perceived the intensity to be 2 RPE units higher than when not wearing the mask.

The mask group wore the ETM during all training sessions. During week 1 , the masks were set to simulate an altitude of $914 \mathrm{~m}$. During week 2, the masks were set to simulate $1829 \mathrm{~m}$. During weeks 3 and 4, the masks were set to simulate $2743 \mathrm{~m}$. During weeks 5 and 6 , the masks were set to simulate $3658 \mathrm{~m}$.

Oxygen saturation $\left(\mathrm{SpO}_{2}\right)$ and blood lactate concentration [BLa] were also obtained in order to quantify the intensity of training. Blood lactate was measured during weeks 2, 4 and 6 of training using a capillary blood sample (Accusport Lactate Analyzer, Accusport, Hawthorne, NY). A finger pulse oximeter was used to measure $\mathrm{SpO}_{2}$ during weeks 4 and 6, using an Allegiance OxiReader 2000 (Allegiance Health Care, McGraw Park, IL).

After completion of the training program, subjects in both the control and mask groups completed the identical test battery as the pretesting.

\section{Statistical analysis}

Standard descriptive statistics were used to characterize the subject population and to evaluate the responses to training. Pre-testing scores between groups were compared using independent t-tests. Differences between groups over the course of training were determined using repeated measures ANOVA. When there was a significant F-ratio, pairwise comparisons were made using Tukey's post-hoc procedures. Alpha was set at $\mathrm{p}<0.05$ to achieve statistical significance for all analyses.

\section{Results}

Twenty-five subjects began the study; 13 in the mask group and 12 in the control group. Twenty-four subjects completed all 12 training sessions during the 6-week training period. If a session was missed during the week, a make-up session was held on the weekend. One female from the mask group did not complete the last training session or post- $\mathrm{VO}_{2} \max$ testing due to a knee injury and thus was excluded from the analysis. The mask and control groups were similar in age, height, weight and BMI at the start of the study (Table 1).

Table 1. Descriptive characteristics of subjects. Values represent means ( \pm standard deviation).

\begin{tabular}{llcc}
\hline & & $\begin{array}{c}\text { Mask } \\
(\mathbf{n}=\mathbf{1 2})\end{array}$ & $\begin{array}{c}\text { Control } \\
(\mathbf{n}=\mathbf{1 2})\end{array}$ \\
\hline Age (years) & Male (n= 8) & $22.9(3.83)$ & $21.0(2.07)$ \\
& Female (n=4) & $21.0(.82)$ & $20.8(1.26)$ \\
Height (m) & Male (n= 8) & $1.78(6.83)$ & $1.85(9.74)$ \\
& Female (n=4) & $1.65(3.37)$ & $1.69(1.54)$ \\
Weight (kg) & Male (n= 8) & $82.4(14.81)$ & $83.8(13.80)$ \\
& Female (n=4) & $58.8(2.87)$ & $66.1(8.21)$ \\
BMI & Male (n= 8) & $25.9(4.15)$ & $24.4(3.02)$ \\
& Female (n=4) & $21.6(.98)$ & $23.2(2.61)$ \\
\hline
\end{tabular}

Changes in pulmonary function and hematological variables from pre to post-testing are presented in Table 2. There were no significant differences between the 
Table 2. Changes in pulmonary function and hematological variables over the course of the training period. Values represent mean ( \pm standard deviation).

\begin{tabular}{|c|c|c|c|c|}
\hline & & Pre & Post & Change \\
\hline \multirow[t]{2}{*}{ FVC (L) } & Mask & $5.2(1.19)$ & $5.1(1.20)$ & -0.1 \\
\hline & Control & 5.31 .42 & $5.2(1.36)$ & -0.1 \\
\hline \multirow[t]{2}{*}{$\mathrm{FEV}_{1}(\mathrm{~L})$} & Mask & 4.3 (1.03) & $4.4(1.03)$ & +0.1 \\
\hline & Control & 4.3 (1.07) & $4.3(1.04)$ & 0.0 \\
\hline \multirow{2}{*}{ FEV $_{1} /$ FVC (\%) } & Mask & $82.1(7.70)$ & $83.5(7.00)$ & +1.4 \\
\hline & Control & $81.1(5.61)$ & $82.2(5.46)$ & +1.1 \\
\hline \multirow[t]{2}{*}{$\mathrm{MIP}\left(\mathrm{cmH}_{2} \mathrm{O}\right)$} & Mask & 80.1 (27.50) & 88.6 (28.19) & +8.5 \\
\hline & Control & $80.7(29.20)$ & $88.2(34.81)$ & +7.5 \\
\hline \multirow[t]{2}{*}{ Hb } & Mask & 13.7 (1.09) & $13.0(1.00)$ & -0.7 \\
\hline & Control & $14.2(.75)$ & 13.5 (1.24) & -0.7 \\
\hline \multirow[t]{2}{*}{ Hct (\%) } & Mask & $40.5(4.00)$ & $42.1(1.88)$ & +1.6 \\
\hline & Control & $42.9(2.84)$ & $43.8(3.55)$ & +0.9 \\
\hline
\end{tabular}

responses of males and females, thus only group data is presented. There were no significant within or between group changes in FVC, $\mathrm{FEV}_{1}, \mathrm{FEV}_{1} / \mathrm{FVC}(\%), \mathrm{MIP}, \mathrm{Hb}$, or Hct over the course of the training period.

Changes in variables measured during the maximal exercise test are presented in Table 3. There were no significant differences in the responses of males and females, thus only group data are presented. Both the mask and control groups had significant increases in $\mathrm{VO}_{2}$ max and PPO as a result of training, but there was no difference in the magnitude of improvement between groups. Only the mask group had significant improvements in VT, PO at VT, RCT, and PO at RCT from pre to post-testing. Only the changes in RCT and PO at RCT reached statistical significance between groups.

In order to quantify the intensity of training, exercise HR, session RPE, and PO for each session were recorded. Additionally, [BLa] was recorded during weeks 2, 4, and 6 and $\mathrm{SpO}_{2}$ was assessed during weeks 4 and 6 . There were no significant differences in training HR (\% HRmax) between the mask group and the control group over the course of the study and exercise HR was consistent across the 12 sessions (Figure 2). Overall the mask group worked at $92 \pm 4.7 \%$ of HRmax, while the control group worked at $88 \pm 5.7 \%$ of HRmax during the highintensity portion of the intervals.

Session RPE was also consistent across the 12 exercise sessions. However, average session RPE for the mask group (6.2 \pm 0.74$)$ was significantly higher than the control group (5.5 \pm 0.67$)$ (Figure 3).

Average PO during the high-intensity portion of each interval increased steadily across the 12 training sessions in both groups (Figure 4). There was no significant difference in the average workload for the mask group (305 \pm 77.6 Watts) and the control group (300 \pm 68.0 Watts) over the course of the study. However, during sessions 11 and 12, the exercise workloads for the mask group were significantly greater than the control group. During the active recovery portion of each interval the mask group worked at $23 \pm 3.9 \%$ of PPO and the control group worked at $22 \pm 3.6 \%$ of PPO (Figure 4 ).

Blood lactate and $\mathrm{SpO}_{2}$ data are presented in Table 4. There were no significant differences in [BLa] between groups during weeks 2, 4 or 6 . Oxygen saturation was only measured during weeks 4 and 6 and was significantly lower in the mask group compared to the control group (Table 4).

Table 4. Blood lactate (BLA, $\left.\mathrm{mmol}^{-1}\right)^{-1}$ during weeks 2, 4 and 6 and oxygen saturation $\left(\mathrm{SpO}_{2}, \%\right)$ during weeks 4 and 6. Values represent mean ( \pm standard deviation).

\begin{tabular}{cccc}
\hline & Weeks & Mask & Control \\
\hline \multirow{2}{*}{ BLA } & 2 & $10.2(3.0)$ & $11.0(3.5)$ \\
& 4 & $10.1(3.0)$ & $10.1(3.4)$ \\
SpO $_{2}$ & 6 & $10.9(2.9)$ & $9.8(3.3)$ \\
& 4 & $94.4(3.2) *$ & $96.0(1.6)$ \\
& 6 & $93.2(3.0) *$ & $95.8(1.7)$ \\
\hline
\end{tabular}

* Significantly lower than the control group $(\mathrm{p}<0.05)$.

Table 3. Changes in performance variables over the course of the training period. Values represent mean ( \pm standard deviation).

\begin{tabular}{llccc}
\hline & & Pre & Post & Change (\%) \\
\hline VO $_{2} \mathbf{m a x}$ (ml·kg ${ }^{-1} \mathbf{m i n}^{-\mathbf{1}}$ ) & Mask & $44.8(6.4)$ & $52.2(7.5) \#$ & +16.5 \\
& Control & $43.6(6.2)$ & $49.5(7.0) \#$ & +13.5 \\
PPO (watts) & Mask & $276.1(61.8)$ & $313.5(69.4) \#$ & +13.6 \\
& Control & $282.5(52.0)$ & $310.4(56.0) \#$ & +9.9 \\
VT (ml/kg/min) & Mask & $29.4(8.1)$ & $33.5(7.0) \#$ & +14.0 \\
& Control & $29.1(3.6)$ & $29.7(6.9)$ & +2.1 \\
PO at VT (watts) & Mask & $162.5(63.5)$ & $193.8(51.3) \#$ & +19.3 \\
& Control & $158.3(38.9)$ & $172.9(48.2)$ & +9.2 \\
RCT (ml·kg. ${ }^{-1}$ min $^{-1}$ ) & Mask & $39.1(8.1)$ & $43.1(7.2) \#$ & $+10.2^{*}$ \\
& Control & $39.2(5.8)$ & $39.6(6.0)$ & +1.0 \\
PO at RCT (watts) & Mask & $243.4(62.4)$ & $283.3(75.6) \#$ & $+16.4^{*}$ \\
& Control & $262.5(57.9)$ & $272.9(52.7)$ & +4.0 \\
Maximal Heart Rate & Mask & $187(10.4)$ & $187(8.5)$ & $+\mathbf{0 . 0}$ \\
& Control & $186(10.7)$ & $186(9.8)$ & $+\mathbf{0 . 0}$ \\
\hline
\end{tabular}

\# Significantly different than pretest $(\mathrm{p}<0.05) .{ }^{*}$ Change significantly different than control group $(\mathrm{p}<0.05)$. 


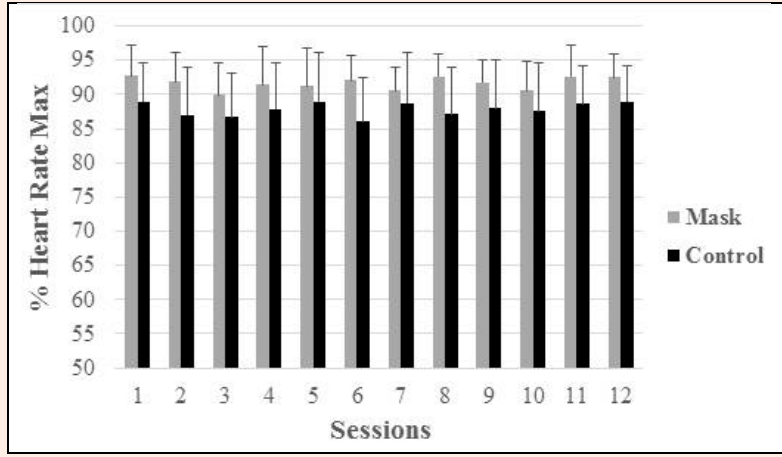

Figure 2. Training heart rate (\% HRmax) for the mask and control groups over the 12 training sessions.

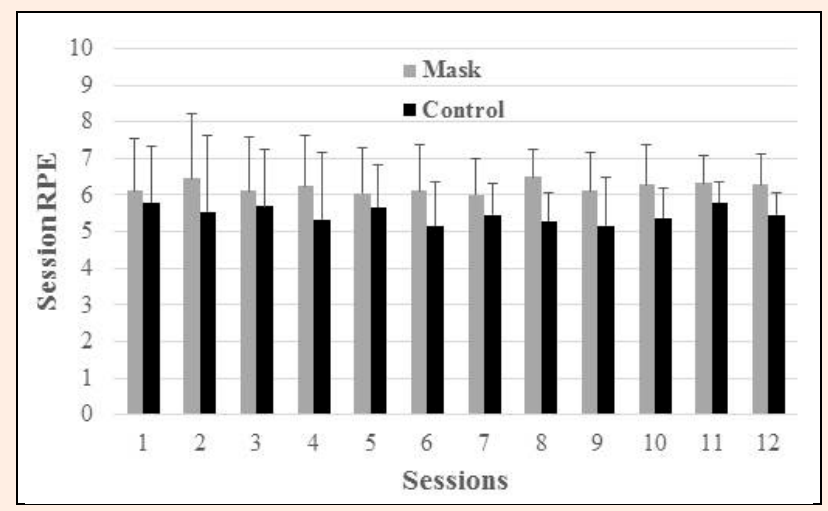

Figure 3. Session RPE of the mask and control groups over the 12 training sessions.

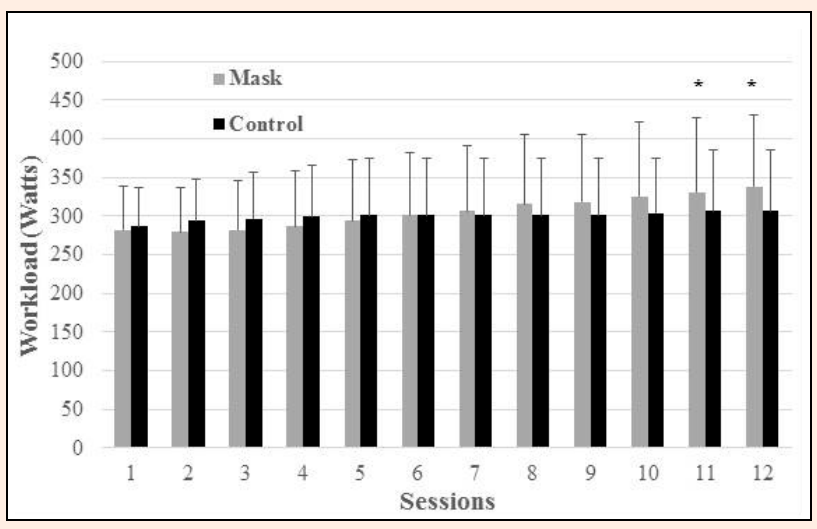

Figure 4. Average workloads of the mask and control groups over the 12 training sessions. *Change significantly different than control group $(\mathrm{p}<0.05)$.

\section{Discussion}

The purpose of this study was to determine the impact of training while wearing the ETM on VT, RCT, $\mathrm{VO}_{2}$ max, PO, lung function and hematological variables. After 6 weeks of a high-intensity cycle ergometer training program, it was found that both the control group and the mask group significantly improved $\mathrm{VO}_{2} \max$ and PPO.
However, only the mask group had significant improvements in VT, PO at VT, RCT, and PO at RCT from pre to post-testing. The trend for improvement in $\mathrm{VT}$ and $\mathrm{PO}$ at VT between groups was similar to the improvements in RCT and PO at RCT, but did not reach statistical significance (VT p $=0.06, \mathrm{PO}$ at VT p $=0.170$ ). There were no significant differences in lung function parameters or hematological variables in either group.

When looking at $\mathrm{VO}_{2} \max$ and PPO, the control group increased $\mathrm{VO}_{2}$ max by $13.5 \%$, and PPO by $9.9 \%$ versus increases in $\mathrm{VO}_{2}$ max of $16.5 \%$ and PPO by $13.6 \%$ in the mask group. Kido et al. (2013) found similar results after 6 weeks of continuous exercise comparing resistive breathing during exercise to exercise alone. The resistive breathing group improved $\mathrm{VO}_{2}$ max by $18.5 \%$ and PPO by $11.1 \%$ and the control exercise group improved by $\mathrm{VO}_{2}$ max by $11.7 \%$ and $\mathrm{PPO}$ by $11.5 \%$. The improvements in $\mathrm{VO}_{2}$ max and PPO were not significantly different between groups.

Although the training program elicited significant improvements in $\mathrm{VO}_{2}$ max and $\mathrm{PPO}$ in both groups, only the mask group had significant improvements in VT, PO at VT, RCT and PO at RCT. Pre to post-testing improvements for the mask group were $13.9 \%$ for VT, $19.3 \%$ for PO at VT, $10.2 \%$ for RCT, and $16.4 \%$ for PO at RCT. Kido et al. (2013) also found similar improvements in VT (36\%) while using a resistive breathing mask during exercise, but no significant improvement in VT was observed in the exercise only group.

Oxygen saturation tended to be lower in the mask group during exercise, but overall $\mathrm{SpO}_{2}$ was only 2\% lower in the mask group than control group (94\% versus 96\%). These values represent a normal drop in $\mathrm{SpO}_{2}$ during high intensity exercise (Romer et al., 2005). Granados et al. (2016) compared the physiologic responses to an ETM-like mask and a sham mask. When worn during a 20 -minute treadmill workout at $60 \%$ of $\mathrm{VO}_{2}$ peak, $\mathrm{SpO}_{2}$ responses averaged $94 \%, 91 \%$ and $89 \%$, for the sham, $2743 \mathrm{~m}$ and $4572 \mathrm{~m}$ altitude simulator settings, respectively. It should be noted that at the same simulated altitude settings as the current study, Grandados et al. (2016) observed lower $\mathrm{SpO}_{2}$ values. This could be due to the nature of the exercise performed. The current study used interval training versus continuous in their study. During interval training, the subject has a recovery period that would allow $\mathrm{SpO}_{2}$ values to recover. When actually ascending to altitude, there are typically much more dramatic decreases in saturation. At altitudes of 914 m, 1829 m, 2743 m, $3658 \mathrm{~m}$, and 4572m saturation levels typically fall to $97 \%$, 95\%, 89\%, 79\%, and 63\%, respectively (altitude.org), which are much greater than seen while wearing the mask at those same altitude settings.

Regardless, Roels et al. (2005) found that 4 weeks of interval training in hypoxic conditions $(\sim 114 \mathrm{~min} \cdot \mathrm{wk}$ ${ }^{1}$ ) did not elicit increases in performance or hematological variables compared to normoxic training. In the current study total time spent in "hypoxic" conditions was only $60 \mathrm{~min} \cdot \mathrm{wk}^{-1}$. Suggesting that if the ETM induced hypoxic conditions, the exposure stimulus would not be enough to cause hematological changes. The failure to significantly 
observe oxygen desaturation and changes in hematological variables suggests that the ETM works more like an inspiratory muscle training device than a simulator of altitude.

Respiratory muscle training devices have reportedly benefited healthy young individuals, athletic populations, and clinical patients (Crisafulli et al., 2007; HajGhanbari et al., 2013; Romer et al., 2002; Volianitis et al., 2001). The pressure threshold loading technique allows a variation in loading at an identifiable intensity or resistance, which makes it a popular model for use in populations looking to specifically gain respiratory strength. Researchers have initiated the process to identify the optimal training intensity for individual populations (Enright and Unnithan, 2011). In order for the ETM to be used as a RMT, further studies are needed to determine what resistance the simulated altitude settings provide to the user.

There were no significant changes within or between groups in lung function parameters measured in the current study. Similarly, Kido et al. (2013) reported no significant improvement in lung function between groups as measured by vital capacity, FVC, $\mathrm{FEV}_{1}$, and MIP. However, there was a significant improvement in maximal voluntary ventilation (MVV) in the resistive breathing group only. Maximal voluntary ventilation was not measured in the current study. Further studies should evaluate the ETMs effect on lung function parameters beyond those looked at in the current study.

There was no significant difference in the average workload between the mask group (305 \pm 77.6 Watts) and the control group (300 \pm 68.0 Watts) over the course of the study. However, during sessions 11 and 12, the exercise workloads for the mask group were significantly greater than the control group. It is unlikely that a difference in workload during the last week of the study could account for the substantial increase in performance variables seen with the mask group. Workload was titrated according to RPE. For the control group, if the last interval was identified as $\leq 5$, for two consecutive sessions, workload was increased by $0.5 \mathrm{~kg}(\approx 30 \mathrm{~W})$ for subsequent sessions. For the mask group, if the last interval was identified as $\leq 7$ for two consecutive sessions, workload was increased by $0.5 \mathrm{~kg}(\approx 30 \mathrm{~W})$ for subsequent sessions. This was based upon observation during pilot testing, where RPE was 2 units higher at identical workloads when wearing the mask. This finding is supported by Granados et al. (2016), who observed that individuals who wore the ETM-like mask had significantly higher RPE throughout a 30-minute treadmill exercise session. Additionally, Gething et al. (2004) found that after 6 weeks of IMT at $100 \%$ of MIP, RPE was significantly decreased. It was suggested that IMT may provide an improvement in physiological conditioning that produces a reduction in perceived cost of breathing. In the current study it was suggested that because the ETM functions as a RMT device there may be a physiologic adaptation allowing subjects to perceive the work as less hard than before.

Because breathing through the mask was restrictive, it was felt that trapping and rebreathing of $\mathrm{CO}_{2}$ could be occurring. A posteriori pilot study was done with four subjects. Each subject completed three sets of intervals under mask and no mask conditions, while end tidal $\mathrm{CO}_{2}$ was measured. It was found that when breathing through a normal Oxycon ${ }^{\mathrm{TM}}$ mobile mask, end tidal $\mathrm{CO}_{2}$ averaged $32.9 \pm 6.0 \mathrm{mmHg}$. When wearing the ETM mask, end tidal $\mathrm{CO}_{2}$ was $55.6 \pm 12.4 \mathrm{mmHg}$. It was thought that the intermittent exposure to increased $\mathrm{CO}_{2}$ levels could have caused an additional respiratory adaptation, decreasing the rate of fatigue in the respiratory muscles.

\section{Conclusion}

The current study found while both the control and mask groups significantly improved in $\mathrm{VO}_{2}$ max and $\mathrm{PPO}$, only the mask group significantly improved VT, PO at VT, RCT and PO at RCT while wearing the ETM after a 6week high-intensity cycle ergometer training. The relatively large improvements in VT, PO at VT, RCT, and PO at RCT while wearing the mask could have very significant performance implications. Although the ETM purportedly simulates altitude training there were no changes in hematological variables pre to post-training or significant changes in $\mathrm{SpO}_{2}$ during training. Therefore, it was suggested that the ETM works more like a RMT device. However, there were no significant within or between group changes in lung function variables measured. Future studies should evaluate the ETM effect on MVV after training. Additional studies are needed to determine the exact resistance that the ETM provides during respiratory muscle training as well as if improvements in VT, PO at VT, RCT and PO at RCT translate to improved performance in athletes.

\section{Acknowledgements}

This study was funded by the American Council on Exercise, San Diego, CA. There were no conflicts of interest.

\section{References}

Balke, B., Nagle, J.F. and Daniels J. (1965) Altitude and maximum performance in work and sports activity. Journal of the American Medical Association 194(6), 176-179.

Boutellier, U., Buchel, R., Kundert, A. and Spengler, C. (1992) The respiratory system as an exercise limiting factor in normal trained subjects. European Journal of Applied Physiology and Occupational Physiology 65, 347-353.

Boutellier, U. and Piwko, P. (1992) The respiratory system as an exercise limiting factor in normal sedentary subjects. European Journal of Applied Physiology and Occupational Physiology 64, 145-152.

Buchheit, M., Kuitunen, S., Voss, S.C., Williams, B.K., MendezVillanueva, A. and Bourdon, P.C. (2012). Physiological strain associated with high-intensity hypoxic intervals in highly trained young runners. Journal of Strength and Conditioning Research 26(1), 94-105.

Borg, G.A. (1982). Psychophysical bases of perceived exertion. Medicine and Science In Sports and Exercise 14, 377-381.

Chapman, R.F., Stray-Gundersen, J. and Levine, B.D. (1998) Individual variation in response to altitude training. Journal of Applied Physiology 85, 1448-1456.

Crisafulli, E., Costi, S., Fabbri, L. and Clini, E. (2007) Respiratory muscles training COPD patients. International Journal of COPD 2(1), 19-25.

Daniels, J. and Oldridges, N. (1969). The effects of alternate exposure to altitude and sea level on world class middle-distance runners. Medicine and Science in Sports 2(3), 107-112.

Enright, S.J. and Unnithan, V.B. (2011) Effect of inspiratory muscle 
training intensities on pulmonary function and work capacity in people who are healthy: a randomized controlled trial. Physical Therapy 91(6), 894-905.

Foster, C., Florhaug, J.A., Franklin, J., Gottschall, L., Hrovatin, L.A., Parker, S., Doleshal, P. and Dodge, C. (2001) A new approach to monitoring exercise training. Journal of Strength and Condi tioning Research 15(1), 109-115.

Foster, C. and Cotter, H.M. (2006) Blood lactate, respiratory and heart rate markers of the capacity for sustained exercise. In: Physiology assessment of human fitness. Ed: Maud, P.J. and Foster, C. $2^{\text {nd }}$ edition, Human Kinetics Press. 63-76.

Gething, A.D., Passfield, L. and Davies, B. (2004) The effects of different inspiratory muscle training intensities on exercising hear rate and perceived exertion. European Journal of Applied Physiology 92, 50-55.

Granados, J., Gillum, T.L., Castillo, W., Christmas, K.M. and Kuennen, M.R. (2016) Functional respiratory muscle training during endurance exercise causes modest hypoxemia but overall is wel tolerated. Journal of Strength and Conditioning Research 30(3), 755-762.

HajGhanbari, B., Yamabayashi, C., Buna, T.R., Coelho, J.D., Freedman, K.D., Morton, T.A, Palmer, S.A., Toy, M.A., Walsh, C., Sheel, A.W. and Reid, W.D. (2013) Effects of respiratory muscle training on performance in athletes: a systematic review with meta-analyses. The Journal of Strength and Conditioning Research 27(6), 1643-1663.

Julian, C.G., Gore, C.J., Wilber, R.L., Daniels, J.T., Fredericson, M., Stray-Gundersen, J., Hahn, A.G., Parisotto, R. and Levine, B.D. (2003) Intermittent normobaric hypoxia does not alter performance or erythropoietic markers in highly trained distance runners. Journal of Applied Physiology 96, 1800-1807.

Kido, S., Nakajima, Y., Miyasaka, T., Maeda, Y., Tanaka, T., Yu, W., Maruoka, H. and Takayanagi, K. (2013) Effects of combined training with breathing ressitance and sustained physical exertion to improve endurance capacity and respiratory muscle function in healthy young adults. Journal of Physical Therapy Science 25, 605-610.

Levine, B.D., Stray-Gundersen, J., Duhaime, G., Snell, P.G. and Friedman, D.B. (1991) Living high-training low: the effect of altitude acclimatization/normoxic training in trained runners. Medicine and Science in Sports and Exercise 23, S25.

Levine, B.D. and Stray-Gundersen, J. (1997) "Living high-training low": effect of moderate-altitude acclimatization with lowaltitude training on performance. Journal of Applied Physiology (Bethesda, Md.: 1985) 83(1), 102-112.

Markov, G., Spengler, C.M., Knopfli-Lenzin, C., Stuessi, C. and Boutellier, U. (2001) Respiratory muscle training increases cycling endurance without affecting cardiovascular responses to exercise. European Journal of Applied Physiology 85, 233-239.

Mattila, V. and Rusko, H. (1996) Effect of living and training low on sea level performance in cyclists. Medicine and Science in Sports and Exercise 28, S156.

McLean, B.D., Gore, C.J. and Kemp, J. (2014). Application of "live high-train low" for enhancing normoxic exercise performance in team sport athletes. Sports Medicine 44(9), 1275-1287.

Paula, P. and Niebauer, J. (2012) Effects of high altitude training on exercise capacity: fact or myth. Sleep and Breathing 16(1), 233239.

Roberts A.D., Clark, S.A., Townsend, N.E., Anderson, M.E., Gore, C.J. and Hahn, A.G. (2003) Changes in performance, maximal oxygen uptake and maximal accumulated oxygen deficit after 5,10 , and 15 days of live high: train low altitude exposure. European Journal of Applied Physiology 88, 390-395.

Robertson, E.Y., Saunders, P.U., Pyne, D.B., Gore, C.J. and Anson, J.M. (2010) Effectiveness of intermittent training in hypoxia combined with live high/train low. European Journal of Applied Physiology 110(2), 379-387.

Roels, B., Millet, G.P., Marcoux, C.J.L., Coste, O., Bentley, D.J. and Candau, R.B. (2005) Effects of hypoxic interval training on cycling performance. Medicine and Science in Sports and Exercise 37(1), 138-146.

Romer, L.M., Haverkamp, H.C., Lovering, A.T., Pegelow, D.F. and Dempsey, J.A. (2005) Effect of exercise-induced arterial hypoxemia on quadriceps muscle fatigue in healthy humans. American Journal of Physiology Regulatory Integrative and Comparative Physiology 290(2), 365-375.
Romer, L.M., McConnell, A.K. and Jones, D.A. (2002) Inspiratory muscle fatigue in trained cyclists: effects of inspiratory muscle training. Medicine and Science in Sports and Exercise 34(5), 785-792.

Romer, L.M., McConnell, A.K. and Jones, D.A. (2002). Effects of inspiratory muscle training on time-trial performance in trained cyclists. Journal of Sports Sciences 20, 547-562.

Rusko, H., Tikkanen, H., Paavolainen, L., Hamalainen, I., Kalliokoski, K. and Puranen, A. (1999) Effect of living in hypoxia and training in normoxia on sea level $\mathrm{VO}_{2} \max$ and red cell mass. Medicine and Science in Sports and Exercise 31 S86.

Rusko, H.K., Tikkanen, H.O. and Peltonen, J.E. (2004) Altitude and endurance training. Journal of Sports Science 22, 928-945.

Stray-Gundersen, J., Chapman, R.F. and Levine, B.D. (2001) Living high-training low altitude training improves sea level performance in male and female elite runners. Journal of Applied Physiology 1(3), 1113-1120.

Volianitis, S., McConnell, A., Koutedakis, Y., McNaughton, L. and Jones, D.A. (2001) Inspiratory muscle training improves rowing performance. Medicine and Science in Sports and Exercise 33(5), 803-809.

\section{Key points}

- Wearing the ETM during a 6-week high-intensity cycle ergometer training program may improve performance variables, such as $\mathrm{VO}_{2} \max , \mathrm{PPO}, \mathrm{VT}$, $\mathrm{PO}$ at VT, RCT and PO at RCT.

- Wearing the ETM did not improve lung function, inspiratory muscle strength, or stimulate changes in hemoglobin or hematocrit levels.

- The ETM does not simulate altitude, but works more like an respiratory training device.

\section{AUTHOR BIOGRAPHY}

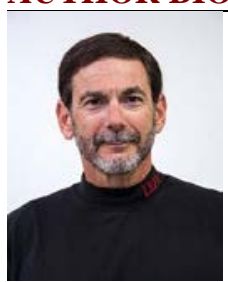

John P. PORCARI

Employment

Professor in the Department of Exercise and Sport Science at the University of Wisconsin-La Crosse

Degree

$\mathrm{PhD}$

\section{Research interests}

Testing new pieces of exercise equipment and new training regimes that come on the market

E-mail: jporcari@uwlax.edu

\section{Lauren PROBST}

Employment

Data Analyst at Froedtert Hospital and the Medical College

of Wisconsin

Degree

MSc

Research interests

Clinical Exercise Physiology

E-mail: Lauren.probst@froedtert.com

\section{Karlei FORRESTER}

Employment

Case Manager at Albany General Hospital in Albany, Ore-

gon

Degree

MSc

Research interests

Clinical Exercise Physiology

E-mail: kforrester@samhealth.org 


\section{Scott DOBERSTEIN}

Employment

Professor in the Exercise and Sports Science Department at

the University of Wisconsin-La Crosse

Degree

MSc

Research interests

Lower extremity injury clinical evaluation techniques, therapeutic modalities

E-mail: sdoberstein@uwlax.edu

\section{Carl FOSTER}

Employment

Professor in the Department of Exercise and Sport Science at the University of Wisconsin-La Crosse

Degree

$\mathrm{PhD}$

Research interests

Exercise physiology, ranging from high performance sports physiology to clinical exercise physiology

E-mail: cfoster@uwlax.edu

\section{Maria L. CRESS}

Employment

Teaching Assistant, Department of Sports and Exercise

Science, University of Wisconsin-La Crosse

\section{Degree}

MSc

Research interests

Clinical Exercise Physiology

E-mail: cress.mari@uwlax.edu

\section{Katharina SCHMIDT}

Employment: Postdoctoral Researcher, Department of Sports

Medicine, Goethe-University, Frankfurt/Main, Germany

Degree

$\mathrm{PhD}$

Research interests

Exercise therapy/interventions; Physical activity and health;

Exercise Testing; Exercise Intensity Prescription

E-mail: Schmidt@sport.uni-frankfurt.de

\section{$\triangle$ John P. Porcari, PhD}

Department of Exercise and Sport Science at the University of Wisconsin-La Crosse, USA 